\title{
Alguns Erros Populares Acerca do Escopo e Método da Economia - Parte $2^{*}$
}

\author{
Ludwig von Mises**
}

\begin{abstract}
Resumo: O texto critica alguns erros comuns sobre a finalidade e o método adequado para a ciência econômica. Aponta falácias conhecidas, como a de que a economia seja um jogo de soma zero, a da onipotência da mente humana, a da infalibilidade das maiorias e a crença em um sistema de governo perfeito, entre outras. Por fim, mostra o método adequado para as ciências que lidam com a ação humana.
\end{abstract}

Palavras-chave: Economia, Escopo e Método, Erros, Metodologia, Ação Humana.

\section{On Some Popular Errors Concerning the Scope and Method of Economics - Part 2}

\begin{abstract}
The text criticizes some common mistakes on the purpose and the appropriate method for economics. Points known fallacies, such as consider the economy as a zero sum game, the omnipotence of the human mind, the infallibility of majorities and the belief in a perfect system of government, among others. Finally, he shows the proper method for the sciences dealing with human action.
\end{abstract}

Keywords: Economics, Scope and Method, Errors, Methodology, Human Action.

Classificação JEL: B41, B25

\footnotetext{
* Texto publicado pela primeira vez em inglês no ano de 1962 como quinto capítulo do livro The Ultimate Foundations of Economic Science. A presente tradução foi feita a partir da seguinte edição: MISES, Ludwig von. Some Preliminary Observations Concerning Praxeology Instead of an Introduction. In: The Ultimate Foundation of Economic Science. Pref. Israel Kirzner. Irvington-on-Hudson: Foundation for Economic Education, $3^{\mathrm{a}}$ ed., 2002. p. 87-103. A primeira parte do texto foi publicada na edição anterior (Volume II, Número 1) de MISES: Revista Interdisciplinar de Filosofia, Direito e Economia.

Traduzido do original em inglês para o português por Márcia Xavier de Brito.
}

${ }^{*}$ Ludwig von Mises nasceu em 29 de setembro de 1881 na cidade de Lviv, atualmente na Ucrânia e na época parte do território do Império Austro-Húngaro. Estudou, a partir de 1900, na Universidade de Viena, e recebeu o título de Doutor em Direito por essa mesma instituição em 1906. Lecionou na Universidade de Viena de 1913 a 1934, no Instituto Universitário de Altos Estudos Internacionais em Genebra de 1934 a 1940 e na New York University de 1945 a 1969. É autor de centenas de artigos acadêmicos e de mais de vinte livros dentre os quais se destaca o tratado de economia Ação Humana (Instituto Ludwig von Mises Brasil, 2010). Faleceu no dia 10 de outubro de 1973 em Nova York, nos Estados Unidos. 


\section{VII - ReAlidade E Jogo}

As condições naturais da existência dos ancestrais não humanos do homem prescreviam a necessidade de uma luta inclemente entre os pares até a morte. Associado ao caráter animal do homem está o impulso de agressão, o ímpeto de aniquilar todos os que com ele competem na tentativa de obter uma porção suficiente dos meios escassos de subsistência que não bastam para a sobrevivência de todos os já nascidos. Somente para o animal mais forte havia a chance de permanecer vivo.

$\mathrm{O}$ que distingue o homem dos brutos é a substituição da inimizade mortal pela cooperação social. O instinto inato de agressão é suprimido a menos que desintegre o esforço combinado para preservar a vida e torná-la mais satisfatória por servir especificamente aos desejos humanos. Para acalmar as necessidades reprimidas, mas não extinguir plenamente aquelas voltadas para a ação violenta, lançamos mão de guerras e jogos. Aquilo que outrora fora extremamente sério, na ocasião era desportivamente replicado como um passatempo. O torneio parece uma luta, mas é apenas um cortejo. Todos os movimentos dos jogadores são estritamente controlados pelas regras do jogo. A vitória não consiste no aniquilamento da outra parte, mas em conseguir chegar a essa situação que as regras declaram ser bem-sucedida. Os jogos não são realidade, mas mera diversão. São o escape do homem civilizado para instintos de inimizade profundamente enraizados. Quando um jogo vem a ser um fim, vitoriosos e vencidos apertam as mãos e voltam à realidade da vida social, que é de cooperação e não de luta.

Dificilmente poderíamos interpretar erroneamente, de modo mais basilar, a essência da cooperação social e da tentativa econômica da humanidade civilizada do que olhar para isso como se fosse uma luta ou a réplica de uma luta, um jogo. Na cooperação social, todos, ao servir aos próprios interesses, servem aos interesses dos demais. Levados pelo impulso de melhorar as próprias condições, a pessoa acaba por melhorar as condições dos outros. $\mathrm{O}$ padeiro não prejudica aqueles para quem assa o pão; ele os serve. Todas as pessoas seriam lesadas se o padeiro parasse de produzir pão e o médico deixasse de atender aos doentes. $\mathrm{O}$ sapateiro não recorre à uma "estratégia" para frustrar os consumidores ao oferecer-lhes sapatos. A competição no mercado não deve ser confundida com a competição biológica implacável que prevalece entre animais e plantas, ou com guerras ainda travadas entre - infelizmente, não ainda de todo nações civilizadas. A competição catalática no mercado destina-se a atribuir a cada indivíduo uma função no sistema social em que possa prestar a todos os demais o serviço mais valioso que seja capaz de realizar.

Sempre existem pessoas que são emocionalmente inaptas para conceber o princípio da cooperação em um sistema de divisão de tarefas. Podemos tentar compreender timologicamente essa debilidade. A compra de qualquer bem reduz o poder de compra do comprador para adquirir qualquer outro bem que também deseje possuir, embora, é claro, considere essa aquisição como algo menos importante que o bem que, na realidade, compra. Desse ponto de vista, considera qualquer compra que faz como um obstáculo que o impede de satisfazer alguns outros desejos. Caso não compre A, ou se tem de gastar menos por A, ele seria capaz de adquirir B. Há, para as pessoas de visão curta, um só passo para a inferência de que é o vendedor de A que o força a abster-se de B. Vê no vendedor não o homem que torna possível satisfazer um de seus desejos, mas o homem que o impede de satisfazer alguns dos outros desejos. O tempo frio o motiva a comprar combustível para a fornalha e reduz os recursos financeiros que pode gastar em outras coisas. No entanto, ele não culpa o tempo nem o anseio de se aquecer, põe a culpa no comerciante de carvão. Esse homem maléfico, pensa, lucra da sua dificuldade.

Tal foi o raciocínio que levou as pessoas a concluir que a fonte da qual o comerciante 
lucra repousa na necessidade e sofrimento do próximo. Segundo esse raciocínio, o médico ganha a vida da doença do paciente e não da cura. As padarias prosperam pela fome, não porque oferecem os meios de apaziguar a fome. Nenhum homem pode lucrar senão às expensas de outros homens; o ganho de alguém é necessariamente a perda de outrem. Em um ato de troca somente o vendedor ganha, ao passo que o comprador sai-se mal. O comércio beneficia os vendedores ao prejudicar os compradores. A vantagem do comércio exterior, diz a doutrina mercantilista, antiga e moderna, consiste em exportar e não na importação adquirida pelas exportações'.

A luz dessa falácia, o interesse do comerciante é prejudicar o público. Sua habilidade é a estratégia, por assim dizer, de infligir o maior malefício possível ao inimigo. Os adversários, cuja ruína trama, são os possíveis consumidores, bem como seus competidores, aqueles que como ele mesmo, embarcam em incursões contra o povo. O método mais apropriado para investigar, cientificamente, as atividades mercantis e o processo de mercado é analisar o comportamento e a estratégia das pessoas engajadas nos jogos ${ }^{2}$.

Em um jogo há um prêmio definido que cabe ao vencedor. Se o prêmio é dado por um terceiro, a parte vencida sai de mãos vazias. Se o prêmio é formado pelas contribuições dos jogadores, o derrotado perde o dinheiro apostado em benefício da parte vitoriosa. Em um jogo há ganhadores e perdedores. Entretanto, um acordo comercial é sempre vantajoso para ambas as partes. Se tanto o comprador como o vendedor não considerarem a transação como a ação mais vantajosa que poderiam escolher sob

\footnotetext{
${ }^{1}$ MISES, Ludwig von. Ação Humana. Trad. Donald Stewart Jr. São Paulo: Instituto Ludwig von Mises Brasil, 2010. p. 757ss.

${ }^{2}$ NEUMANN, J. V. \& MORGENSTERN, O. Theory of Games and Economic Behavior. Princeton: Princeton University Press, 1944; LUCE, R. Ducan \& RAIFFA, H. Games and Decisions. New York: John Wiley \& Sons, 1957; dentre muitos outros livros e artigos.
}

as condições reinantes, não entrariam na negociação ${ }^{3}$.

É verdade que o negociar, bem como o jogar é um comportamento racional. Também o são, todavia, todas as outras ações do homem. $\mathrm{O}$ cientista nas pesquisas, o assassino ao planejar o crime, o candidato a um cargo público ao buscar votos, o juiz na busca da decisão justa, o missionário nas tentativas de converter um infiel, o professor ao instruir seus pupilos, todos agem racionalmente.

Um jogo é um passatempo, é um meio de empregar o tempo livre e banir o tédio. Envolve custos e pertence à esfera do consumo. Entretanto, os negócios são um meio - o único meio - para aumentar a quantidade de bens à disposição para preservar a vida e torná-la mais agradável. Nenhum jogo pode, além do prazer que proporciona aos jogadores e espectadores, contribuir em nada para a melhoria da condição humana4. É um erro equiparar os jogos com as conquistas da atividade comercial.

A busca de uma melhoria nas condições de existência impele o homem à ação. Ação requer planejamento e a decisão sobre qual dos vários planos é o mais vantajoso. No entanto, esse traço distintivo dos negócios não é o que lhe impõe tal tomada de decisão, mas é a que visa a melhoria das condições de vida. Jogos são folguedos, esporte e diversão; negócios são vida e realidade.

\section{VIII - A InTERpretaçÃo ERrada do Clima de Opinião}

Ninguém explica uma doutrina e as ações por ela engendradas caso declare que foi gerada pelo espírito da época ou pelo meio pessoal ou geográfico dos atores. Ao recorrer a tais interpretações, tal pessoa simplesmente

\footnotetext{
${ }^{3}$ MISES. Ação Humana. p.758

4 Jogos planejados para o entretenimento dos espectadores não são propriamente jogos, mas show business.
} 
enfatiza o fato de que uma ideia definida foi um acordo com outras ideias havidas por outras pessoas ao mesmo tempo e no mesmo meio social. O que é chamado de espírito de época, dos membros de uma coletividade ou de um determinado meio social são exatamente as doutrinas que prevalecem entre os indivíduos por elas afetados.

As ideias que mudam o clima de opinião de um determinado ambiente são as nunca dantes ouvidas. Para essas novas ideias não há outra explicação senão a de que houve um homem cuja mente as concebeu.

Uma nova ideia é uma resposta oferecida por seu autor ao desafio das condições naturais ou das ideias desenvolvidas antes por outras pessoas. Aoolhar para trás na história das ideias - e das ações por elas criadas - o historiador deverá descobrir uma tendência definida na sucessão e poderá dizer que "logicamente" a ideia mais antiga fez com que surgisse a ideia mais recente. No entanto, carece a tal filosofia retrospectiva qualquer justificativa racional. A tendência é desmerecer as contribuições do talento - o herói da história intelectual - e atribuir seu trabalho à conjuntura dos acontecimentos só faz sentido na estrutura da Filosofia da História que finge saber o plano secreto que Deus ou um poder sobre-humano (tal como as forças produtivas materiais no sistema de Marx) quer efetuar ao dirigir as ações de todos os homens. Do ponto de vista de tal filosofia todos os homens são fantoches compelidos a se comportar exatamente da maneira que o demiurgo lhes prescreveu.

\section{IX - A Crença na Onipotência do Pensamento}

Uma característica típica das ideias populares de hoje acerca da cooperação social é o que Sigmund Freud (1856-1939) chamou de crença na onipotência do pensamento humano (die Allmacht des Gedankens)5. Essa

${ }^{5}$ FREUD, S. Totem und Tabu. Viena: Hugo Heller, 1913. p. 79ss. crença não é, obviamente, (afora os psicopatas e neuróticos) mantida em relação à esfera que é pesquisada pelas ciências naturais. No campo dos acontecimentos sociais, todavia, é solidamente demonstrada. Evoluiu da doutrina que atribui a infalibilidade às maiorias.

O ponto essencial nas doutrinas políticas do Iluminismo foi a substituição do despotismo real pelo governo representativo. No conflito constitucional na Espanha, em que defensores do governo parlamentar brigavam com as aspirações absolutistas de Fernando VII (1772-1833) de Bourbon, os adeptos do regime constitucional eram chamados de 'liberais' e os adeptos do rei de 'servis'. Logo, o nome 'liberalismo' foi adotado por toda a Europa.

Ogovernorepresentativoouparlamentar (também chamado de governo pelo povo ou governo democrático) é dirigido por altos funcionários públicos designados pela maioria do povo. Demagogos tentam justificá-lo com um balbucio extático a respeito da inspiração sobrenatural das maiorias. No entanto, é um erro grave tentar pressupor que os liberais europeus e norte-americanos do século XIX defenderam-no porque acreditavam na sabedoria infalível, na perfeição moral, na justiça inerente e noutras virtudes do homem comum e, portanto, das maiorias. Os liberais queriam salvaguardar a evolução regular da prosperidade, bem como o bem-estar material e espiritual de todos os povos. Queriam abolir a pobreza e a indigência. Como meio para alcançar tais fins, defenderam instituições dirigidas para a cooperação pacífica de todos os indivíduos em várias nações, bem como, para a paz internacional. Consideraram as guerras, fossem guerras civis (revoluções) ou estrangeiras, como uma perturbação do progresso regular da humanidade rumo a condições mais satisfatórias. Perceberam muito bem que a economia de mercado, a própria base da civilização moderna, envolvia a cooperação pacífica e era destruída quando as pessoas, em vez de trocar bens e serviços, brigavam entre si. 
Por outro lado, os liberais compreenderam muito bem o fato de que o poder dos governantes repousa, em última análise, não na força material, mas nas ideias. Como David Hume (1711-1776) assinalou no famoso ensaio "Of the First Principles of Government" [Sobre o Primeiro Princípio do Governo] ${ }^{6}$, os governantes sempre são a minoria do povo. A autoridade e o poder que possuem de exigir obediência da parte da imensa maioria dos súditos deriva da opinião destes de que servem melhor aos próprios interesses ao serem leais e observarem as ordens dos chefes. Caso essa opinião perca a força, a maioria, cedo ou tarde, promove uma rebelião. A Revolução - guerra civil - removerá um sistema de governo impopular e governantes impopulares e os substituirá por um sistema e por servidores públicos que a maioria considera como mais favorável à promoção de seus anseios. Para evitar tais distúrbios violentos à paz e as perniciosas consequências, para salvaguardar o funcionamento pacífico do sistema econômico, os liberais advogam o governo pelos representantes da maioria. Esse plano possibilita a mudança no arranjo dos negócios públicos. Torna desnecessário o recurso às armas e ao derramamento de sangue não só no âmbito doméstico como também nas relações internacionais. Quando cada território puder, pelo voto da maioria, determinar se deve formar um Estado independente ou ser parte de um Estado maior, não teremos mais guerras para conquistar mais províncias?

Ao defender o governo pela maioria do povo, os liberais do século XIX não nutriam quaisquer ilusões acerca da perfeição intelectual e moral de muitos, das maiorias.

\footnotetext{
${ }^{6}$ Em português, o ensaio pode ser encontrado em: HUME, David. Ensaios Morais, Políticos e Literários. Trad. Luciano Trigo. Rio de Janeiro: Topbooks, 2004. (N. do T.)

${ }^{7}$ A primeira condição para o estabelecimento da paz perpétua é, certamente, a adoção geral dos princípios do capitalismo laissez-faire. Sobre esse problema, ver: MISES. Ação Humana. p. 778ss. Ver, também: MISES, Ludwig von. Omnipotent Government. New Haven: Yale University Press, 1944.
}

Sabiam que todos os homens são passíveis de erros e que isso poderia ocorrer à maioria, que, enganada por falsas doutrinas propagadas por demagogos irresponsáveis, embarcaria em políticas que findariam em desastres, e até mesmo na destruição de toda a civilização. No entanto, os liberais não estavam menos conscientes do fato de que nenhum método imaginável de governo poderia evitar tal catástrofe. Se a pequena minoria de cidadãos iluminados, capaz de conceber sólidos princípios de gestão política, não tiver sucesso em ganhar o apoio dos cidadãos e convertê-lo em endosso de políticas que tragam e preservem a prosperidade, a causa da humanidade e da civilização está perdida. Não há outro meio de salvaguardar um desenvolvimento propício para os assuntos humanos do que fazer com que as massas subordinadas adotem as ideias da elite. Isso tem de ser conquistado pelo convencimento. Não pode ser realizado por um regime despótico que em vez de ilustrar as massas, as submete. No longo prazo, as ideias da maioria, não importando quão prejudiciais possam ser, continuarão. O futuro da humanidade depende da capacidade da elite em influenciar a opinião pública na direção correta.

Esses liberais não acreditavam na infalibilidade de ser algum nem na infalibilidade das maiorias. $\mathrm{O}$ otimismo acerca do futuro baseava-se na expectativa de que a elite intelectual persuadisse a maioria para aprovar políticas benéficas.

A história da última centena de $\operatorname{anos}^{8}$ não consumou tais esperanças. Talvez a transição do despotismo dos reis e das aristocracias tenha ocorrido muito subitamente. De qualquer modo, é fato que a doutrina que imputa excelência moral e intelectual ao homem comum, e a consequente infalibilidade da maioria, tornou-se dogma fundamental da propaganda política "progressista". No desenvolvimento lógico mais remoto gerou a crença de que no campo da organização

${ }^{8}$ Vale notar que este texto foi escrito na década de 1960. (N. do T.) 
política e econômica da sociedade qualquer plano ideado pela maioria pode funcionar de maneira satisfatória. As pessoas não mais perguntam se o intervencionismo ou o socialismo podem levar aos efeitos que os defensores esperam. O mero fato da maioria dos eleitores pedirem por isso é considerada prova irrefutável de que podem funcionar e que, inevitavelmente, resultarão nos benefícios esperados. Nenhum político está mais interessado em se a medida está apta a produzir os fins desejados. Somente interessa a ele saber se a maioria dos eleitores apoia ou rejeita a medida ${ }^{9}$. Pouquíssimas pessoas prestam atenção ao que a "simples teoria" diz a respeito do socialismo e da prática dos "experimentos" socialistas na Rússia e noutros países. Quase todos os nossos contemporâneos acreditam firmemente que o socialismo transformará a Terra em um paraíso. Poderíamos chamar de quimera ou da crença na onipotência do pensamento.

No entanto, o critério de verdade é que isso funciona mesmo que ninguém esteja disposto a reconhecer.

\section{X - O Conceito de um Sistema Perfeito de Governo}

O "engenheiro social" é o reformador que está preparado para "liquidar" todos os que não se ajustarem em seu plano para o arranjo dos assuntos humanos. Entretanto, historiadores e, às vezes, até mesmo as vítimas que condena à morte não são avessas a encontrar algumas circunstâncias atenuantes para os massacres ou carnificinas planejadas ao ressaltar que ele estava, em última análise, motivado por uma nobre ambição: desejava instituir a condição perfeita da humanidade. Atribuem-lhe um lugar na longa linhagem de planejadores de esquemas utópicos.

9 É sintomático dessa mentalidade o peso que os políticos conferem aos resultados das pesquisas de opinião pública.
Ora, certamente é tolice desculpar desse modo assassinos em massa e bandoleiros sádicos como Josef Stalin (1878-1953) e Adolf Hitler (1889-1945). Não há dúvida, todavia, que muitos dos mais sanguinários "liquidadores" foram guiados por ideias que inspiraram, desde tempos imemoriais, as tentativas dos filósofos de refletir sobre uma constituição perfeita. Uma vez que tenham desenhado um plano de tal ordem ideal, o autor põe-se em busca do homem que poderia instituílo ao suprimir a oposição de todos os que discordam. Nesse sentido, Platão estava aflito para encontrar um tirano que utilizasse seu poder para consumar o Estado ideal platônico. A questão se outras pessoas gostariam ou não daquilo que ele mesmo tinha reservado para elas nunca ocorreu a Platão. Estava implícito para ele que o rei que se tornasse filósofo ou o filósofo que se tornasse rei, somente ele, tinha o direito de agir e todas as demais pessoas, sem uma vontade própria, tinham de se submeter às ordens reais. Analisado do ponto de vista do filósofo que está firmemente convencido da própria infalibilidade, todos os dissidentes parecem ser meros rebeldes obstinados a resistir ao que lhes beneficiará.

A experiência conferida pela história, em especial nos últimos duzentos anos, não abalou a crença na salvação pela tirania e no extermínio dos dissidentes. Muitos de nossos contemporâneos estão firmemente convencidos de que o que precisamos para tornar, de fato, satisfatórios todos os assuntos humanos é a brutal supressão de todas as pessoas "más", isto é, daqueles dos quais discordam. Sonham com um sistema perfeito de governo que - como creem - já teria, há muito, percebido esses homens "maus" guiados pela estupidez e pelo egoísmo, e não teria impedido a sua instituição.

Uma escola de reformadores moderna, supostamente científica, rejeita essas medidas violentas e põe a culpa por tudo o que carece a condição humana na suposta falha do que é chamado de "Ciência Política". As ciências naturais, dizem, avançou consideravelmente nos últimos séculos e a tecnologia nos deu, 
quase a cada mês, novos instrumentos que tornam a vida mais agradável. No entanto, "o progresso político foi nulo". O motivo é que a "Ciência Política permaneceu estagnada"10. A Ciência Política deveria adotar os métodos das ciências naturais; não deveria mais perder tempo em especulações, mas deveria estudar os "fatos". Como nas ciências naturais, "antes da teoria são necessários os fatos" 11 .

Dificilmente poderiam interpretar de modo mais lamentável cada aspecto das condições humanas. Ao restringir nossa crítica aos problemas epistemológicos envolvidos, temos de dizer: O que hoje é chamado de "Ciência Política" é um ramo da história que lida com a história das instituições políticas e com a história do pensamento político como manifestada nos escritos de autores que dissertaram sobre instituições políticas e esboçaram planos para alterá-las. Isso é história, e nunca pode, como tal, do modo como assinalamos acima, oferecer "fatos" no sentido que o termo é usado pelas ciências naturais experimentais. Não há necessidade de instar os cientistas políticos a reunir todos os fatos do passado remoto e da história recente, falsamente rotulados de "experiência presente" 12 . Na verdade, fazem todo o possível a esse respeito. E, não faz sentido dizê-los que as conclusões derivam desse dever material "de ser testado por experimentos"13. É desnecessário repetir que as ciências da ação humana não podem realizar nenhum experimento.

Seria disparatado afirmar, de maneira apodítica, que a ciência nunca será bemsucedida ao desenvolver uma doutrina praxiológica apriorística de organização política que põe uma ciência teórica ao lado de uma disciplina puramente histórica de Ciência Política. Tudo o que podemos dizer hoje é que nenhum homem vivo sabe como

10 PARKINSON, N. C. The Evolution of Political Thought. Boston: Houghton Mifflin, 1958. p. 306.

\footnotetext{
${ }^{11}$ Idem. Ibidem., p. 309.

${ }^{12}$ Idem. Ibidem., p. 314.

${ }^{13}$ Idem. Ibidem., p. 314.
}

tal ciência pode ser construída. No entanto, mesmo que tal ramo novo da praxiologia um dia deva surgir, não teria utilidade para o tratamento os problemas que filósofos e estadistas anseiam por resolver.

Que toda ação humana tenha de ser e é julgada pelos frutos ou resultados é um antigo truísmo. É um princípio com o qual os Evangelhos concordam com os, inúmeras vezes mal compreendidos, ensinamentos da filosofia utilitária. O ponto crucial, todavia, é a imensa diferença entre as pessoas na avaliação dos resultados. O que alguns consideram como bom ou o melhor é, com frequência, apaixonadamente rejeitado por outros como totalmente mau. Os utópicos não se importam em nos dizer qual arranjo dos negócios do Estado melhor satisfariam os concidadãos. Simplesmente expõem quais condições para o restante da humanidade seriam mais satisfatórias. Não lhes ocorre e nem aos adeptos que tentam realizar esses planos que existe uma diferença fundamental entre essas duas coisas. Os ditadores soviéticos e seu séquito pensam que tudo é bom na Rússia, desde que eles mesmos estejam satisfeitos.

Contudo, mesmo se por amor à argumentação colocarmos de lado essa questão, temos de sublinhar que o conceito de um sistema perfeito de governo é falacioso e autocontraditório.

O que eleva o homem acima de todos os outros animais é a percepção de que a cooperação pacífica sob o princípio da divisão de trabalho é um método melhor para preservar a vida e para remover o mal-estar do que ceder a uma competição biológica impiedosa para partilhar meios desubsistência escassos oferecidos pela natureza. Guiado por tal discernimento, somente o homem, dentre todos os seres vivos, objetiva conscientemente substituir o que os filósofos chamam de estado de natureza, o bellum omnium contra omnes ou a lei da selva pela cooperação social. Entretanto, para preservar a paz, sendo como são os seres humanos, é indispensável estar prontos para repelir por meio de violência qualquer agressão, seja por parte dos bandidos 
domésticos ou por parte de inimigos externos. Assim, a cooperação humana pacífica, o prérequisito da prosperidade e da civilização não pode existir sem um aparato social de coerção e coação, isto é, sem um governo. Os males da violência, do roubo e do assassinato só podem ser evitados por uma instituição que, por si mesma, sempre que necessário, recorra aos próprios métodos de ação para prevenção pelos quais é instituída. Eis que emerge uma distinção entre o emprego ilegal da violência e o recurso legítimo ao seu uso. Por reconhecer tal fato algumas pessoas dizem ser o governo um mal, muito embora admitam ser um mal necessário. No entanto, o que é necessário para atingir um fim almejado e considerado como benéfico não é um mal na conotação moral do termo, mas um meio, o preço a ser pago. Não obstante, resta o fato de que ações consideradas são altamente censuráveis e criminosas quando perpetradas por indivíduos "não autorizados" e aprovadas, quando cometidas por "autoridades".

O governo, como tal, não é somente um mal, mas a instituição mais necessária e benéfica, sem a qual nenhuma cooperação social duradoura e nenhuma civilização pode progredir e ser preservada. É um meio de lidar com a imperfeição inerente de muitos, talvez da maioria das pessoas. Se todas as pessoas fossem capazes de perceber que a alternativa à cooperação social pacífica é a renúncia a tudo que o distingue o Homo sapiens dos animais de rapina, e se todos tivessem a força moral sempre para agir corretamente, não haveria necessidade alguma de instituir um aparato social de coerção e opressão. Não é o Estado que é um mal, mas as falhas da razão e do caráter humanos que requerem, imperativamente, a atividade de um poder de polícia. O governo e o Estado nunca podem ser perfeitos porque devem suas raison d'être à imperfeição do homem e podem alcançar seus fins, a eliminação do inato impulso humano à violência, somente pelo recurso à violência, a coisa mesma a que são convocados a prevenir.

É um expediente de dois gumes confiar ao indivíduo ou a um grupo de indivíduos a autoridade de recorrer à violência. A tentação que isso encerra é demasiado tentadora para um ser humano. Os homens que devem proteger a comunidade da agressão violenta facilmente transformam-se nos mais perigosos agressores. Transgridem o mandato. Utilizam mal o poder para oprimir aqueles que supostamente defenderiam da opressão. O principal problema político é como evitar que o poder de polícia se torne tirânico. Esse é o significado de todas as lutas pela liberdade. A característica essencial da civilização ocidental que a distingue das civilizações presas e petrificadas do Oriente foi e é a preocupação de tornarmo-nos livres do Estado. A história do Ocidente, da época da pólis dos gregos à resistência ao socialismo dos dias de hoje, é essencialmente a luta pela liberdade contra a usurpação dos funcionários públicos.

Uma escola rasa de filósofos sociais, os anarquistas, escolhem ignorar a questão ao sugerir uma estruturação da humanidade sem o Estado. Simplesmente ignoram o fato do homem não ser anjo. São obtusos demais para perceber que, no curto prazo, um indivíduo ou um grupo de indivíduos pode, por certo, promover os próprios interesses à custa dos próprios interesses ou do interesse de terceiros, no longo prazo. Uma sociedade que não esteja preparada para impedir os ataques de agressores antissociais ou de pouca visão é impotente e está à mercê dos membros menos inteligentes e mais brutais. Ainda que Platão tenha fundado sua utopia na esperança de que um pequeno grupo de filósofos de perfeita sabedoria e moral impecável estivessem disponíveis para a condução suprema dos assuntos, os anarquistas supõem que todos os homens, sem exceção, serão dotados de perfeita sabedoria e impecabilidade moral. Erram ao imaginar que nenhum sistema de cooperação social possa eliminar o dilema entre o interesse de um homem ou de um grupo no curto prazo e os que surgirão no longo prazo.

A propensão atávica do homem em forçar a submissão das demais pessoas 
manifesta-se claramente na popularidade desfrutada pelo plano socialista. $\mathrm{O}$ socialismo é totalitário. Somente o autocrata ou o conselho de autocratas são obrigados a agir. Todos os outros homens serão privados de qualquer poder discricionário de escolher e de almejar os fins escolhidos; os oponentes serão liquidados. Ao aprovar tal plano, todo socialista indica, tacitamente, que os ditadores, aqueles aos quais foram confiados o gerenciamento da produção e todas as funções do governo, concordarão exatamente com as suas ideias a respeito do que é desejável e o que é indesejável. Ao deificar o Estado - se é um marxista ortodoxo, chama-o de sociedade - e ao atribuir-lhe poder ilimitado, deifica a si mesmo e intenta a violenta supressão de todos dos quais discorda. $\mathrm{O}$ socialista não vê problema algum na condução dos negócios políticos porque só se importa com a própria satisfação e não leva em conta a possibilidade de que um governo socialista possa proceder de uma maneira que ele não goste.

Os "cientistas políticos" estão livres das ilusões e autoenganos que arruínam o julgamento dos anarquistas e socialistas. No entanto, ocupados com o estudo de um imenso material histórico, tornam-se preocupados com o detalhe, com as inúmeras instâncias de ciúmes mesquinhos, inveja, ambição pessoal e cobiça apresentada pelos atores na cena política. Atribuem o fracasso de todos os sistemas políticos até agora tentados à fraqueza intelectual e moral do homem. Como veem o problema, esses sistemas fracassaram porque o funcionamento satisfatório exigiria homens de qualidade moral e intelectual presentes apenas de maneira excepcional na realidade. Ao partir dessa doutrina, tentam esboçar planos para uma ordem política que possa funcionar automaticamente, por assim dizer, e que não seria enredada pela inaptidão e vícios dos homens. A constituição ideal deveria salvaguardar uma conduta irrepreensível nos negócios públicos apesar da corrupção do povo e dos governantes e da ineficiência. Os que buscam tal sistema legal não se satisfizeram nas ilusões dos utópicos que pressupunham que todos os homens, ou ao menos uma minoria de homens superiores é imaculada e eficiente. Regozijam-se com sua abordagem realista do problema, mas nunca suscitam a questão de como os homens maculados por todas as imperfeições inerentes ao caráter humano podem ser induzidos a se submeter voluntariamente, de modo que os impeça a dar vazão aos caprichos e desejos.

No entanto, a principal deficiência dessa suposta abordagem realista ao problema não é somente essa. É para ser visto na ilusão de que o governo, uma instituição cuja função essencial é o emprego da violência, pode ser operado segundo os princípios da moralidade que condenam peremptoriamente o recurso à violência. $\mathrm{O}$ governo percute a submissão, o aprisionamento e o assassinato. As pessoas podem estar propensas a esquecer disso porque o cidadão obediente à lei submetese humildemente às ordens das autoridades de modo a evitar a punição. Os juristas, todavia, são mais realistas e chamam a lei a qual nenhuma sanção é apensada de lei imperfeita. A autoridade da lei feita pelos homens deve-se, em sua inteireza, às armas dos policiais que compelem à obediência aos dispositivos. Nada do que deve ser dito sobre a necessidade da ação governamental e dos benefícios dela derivados pode retirar ou mitigar o sofrimento dos que estão extenuados nas prisões. Nenhuma reforma poderá tornar perfeitamente satisfatório o funcionamento de uma instituição cuja atividade essencial consiste em infligir dor.

A responsabilidade pelo erro em descobrir um sistema perfeito de governo não repousa no suposto atraso do que é chamado de Ciência Política. Se os homens fossem perfeitos, não haveria a necessidade de governo. Com homens imperfeitos, nenhum sistema de governo pode funcionar de modo satisfatório.

A superioridade do homem consiste nesse poder de escolher os fins e recorrer aos meios para chegar aos fins almejados; as atividades do governo pretendem restringir esse critério dos indivíduos. Todo homem 
pretende evitar o que lhe causa dor. As atividades do governo consistem, em última análise, no infligir dor. Todos os grandes feitos da humanidade foram produto de um esforço espontâneo da parte dos indivíduos; o governo substitui a coerção por ação voluntária. É verdade, o governo é indispensável porque os homens não são irrepreensíveis. Projetado, contudo, para lidar com alguns aspectos da imperfeição humana, nunca pode ser perfeito.

\section{XI - As Cî̂NCIAS \\ Comportamentais}

As pretensas Ciências Comportamentais desejam lidar, cientificamente, com o comportamento humano ${ }^{14}$. Rejeitam como "não científico" e "racionalista" os métodos da Praxiologia e da Economia, Por outro lado, denigrem a história por ser antiquada e sem quaisquer aplicações práticas para a melhoria das condições humanas. A suposta disciplina que apresentam irá, prometem, lidar com cada aspecto do comportamento humano e providenciar, portanto, $\mathrm{O}$ conhecimento que prestará inúmeros serviços aos empreendimentos para melhorar a sina da humanidade.

Os representantes dessa nova ciência não estão preparados para perceber que são historiadores e que recorrem aos métodos de pesquisa histórica ${ }^{15}$. $\mathrm{O}$ que com frequência - mas nem sempre - os distingue dos historiadores comuns é que, como os sociólogos, escolhem como o assunto principal das pesquisas as circunstâncias do passado recente e aspectos da conduta humana que a maioria dos historiadores de outrora costumavam negligenciar. Mais extraordinário deve ser o fato de que seus

\footnotetext{
${ }^{14}$ Não podemos confundir as "ciências comportamentais" com behaviorismo. Sobre este último, ver: MISES. Ação Humana. p. 52.

${ }^{15}$ É claro que alguns desses acadêmicos lidam com problemas de medicina e higiene.
}

tratados sempre sugerem uma determinada política, como supostamente "ensinada" pela história, uma postura que a maioria dos historiadores sérios há muito abandonou. Não é nosso objeto criticar os métodos aplicados nesses livros e artigos, nem questionar as predisposições políticas um tanto ingênuas por vezes demonstradas pelos autores. $\mathrm{O}$ que torna conveniente prestar atenção a tais estudos comportamentais é o descuido para com um dos princípios epistemológicos mais importantes da história, o princípio da relevância.

Na pesquisa experimental das ciências naturais tudo que pode ser observado é suficientemente relevante para ser registrado. Como, segundo o a priori que existe no início de toda pesquisa nas ciências naturais, o que quer que aconteça está prestes a acontecer como efeito regular daquilo que o precedeu, todo acontecimento corretamente observado e descritoéum "fato" que tem de ser integrado no corpo teórico de doutrina. Nenhum relato de experiência é sem alguma relevância na totalidade do conhecimento. Como consequência, todo projeto de pesquisa, se realizado de modo cioso e habilidoso, deve ser tido como uma contribuição para o esforço científico da humanidade.

Nas ciências históricas isso é diferente. Lidam com as ações humanas: os juízos de valor que as animam, a usabilidade dos meios escolhidos para a execução e os resultados delas derivados. Cada um desses fatores exerce função própria na sucessão de eventos. A principal tarefa do historiador é designar, tão corretamente quanto o possa, todos os fatores no espectro dos efeitos. Essa quase quantificação, tal determinação da relevância de cada fator, é uma das funções que a compreensão específica das ciências históricas é chamada a realizar ${ }^{16}$.

\footnotetext{
${ }^{16}$ Ver o capítulo 4 [Certainty and Uncertainty] do seguinte livro: MISES, Ludwig von. The Ultimate Foundation of Economic Science. Pref. Israel Kirzner. Irvington-onHudson: Foundation for Economic Education, $3^{\mathrm{a}}$ ed., 2002. Mais precisamente, ver o item 4 [Quantification and Understanding in Acting and in History]. (N. do T.)
} 
No campo da história (no sentido mais amplo do termo) preponderam diferenças consideráveis entre os vários tópicos que poderiam se tornar objeto de atividades de pesquisa. É insignificante e sem sentido determinar, em termos gerais, "o comportamento do homem" como o programa de atividades de uma disciplina. $\mathrm{O}$ homem objetiva a um número infinito de metas e lança mão de um número infinito de meios diferentes para consegui-los. O historiador (ou, nesse caso, o cientista comportamental) deve escolher um tópico de relevância para o destino da humanidade e, portanto, também para a ampliação de nosso conhecimento. Não deve perder o tempo com ninharias. Ao escolher o tema de seu livro, classifica-se. Um pode escrever sobre a história da liberdade, outro, sobre a história do jogo de cartas. Um pode escrever a biografia de Dante Alighieri (1265-1321), outro a biografia de um maître de um hotel chique ${ }^{17}$.

Como os grandes assuntos do passado da humanidade já foram estudados pelas ciências históricas tradicionais, o que restou para as ciências comportamentais são estudos detalhados sobre os prazeres, tristezas e crimes do homem comum. Para coletar material recente sobre esses e outros assuntos similares não é necessária técnica ou conhecimento especial algum. Todo universitário pode ingressar imediatamente em algum projeto. Há um número ilimitado de assuntos para teses de doutorado e tratados consideravelmente maiores. Muitos deles lidam com temas bastante triviais, destituídos de qualquer valor para o aprimoramento de nosso saber.

As assim chamadas Ciências Comportamentais mal necessitam de completa reorientação do ponto de vista do princípio da relevância. É possível escrever um livro volumoso sobre cada um dos assuntos, mas a questão é se tal livro lidará com algo que seja relevante do ponto de vista da teoria e da prática. cos

${ }^{17}$ SCHRIFTGIESSER, Karl. Oscar of the Waldorf. New York: E. P. Dutton, 1943. 